\title{
An impacted oesophageal foreign body in a physically abused child ${ }^{*}$
}

\author{
Olushola Abdulrahman Afolabi", Adeyi Adogwu Adoga, Emmanuel Musa, \\ Alfred Nicholas Bemu, Garba Mainasara Mohammed, Aliyu Mohammed Kodiya, \\ Aminu Bakari, Babagana Mohammed Ahmad
}

National Ear Care Center, Kaduna, Nigeria;

\#Corresponding Author: droaafolabi@yahoo.com, adeyiadoga@gmail.com, patmusae@yahoo.com, drbemualfred@yahoo.com, mgmainas@yahoo.com, dockodiya@yahoo.com, aminubakari@yahoo.com, bmahmad62@yahoo.com

Received 21 March 2013; revised 25 April 2013; accepted 10 June 2013

Copyright (c) 2013 Olushola Abdulrahman Afolabi et al. This is an open access article distributed under the Creative Commons Attribution License, which permits unrestricted use, distribution, and reproduction in any medium, provided the original work is properly cited.

\begin{abstract}
Physicians under-report cases of child abuse or child maltreatment. We present a case of an impacted oesophageal foreign body in a physically abused child. S.H. is a 7-year-old male child who accidentally ingested metal clip while being assaulted by his paternal uncle whom he resides with. He presented with dysphagia, odynophagia and drooling of saliva and urgent $x$-ray soft tissue neck revealing the presence of the metallic foreign body in the prevertebral region. He had emergency oesophagoscopy with the removal of foreign body, did well and was discharged home $4^{\text {th }}$ day postoperatively after parental counselling. It remains the responsibility of paediatric healthcare providers to consider child maltreatment as a differential diagnosis of any unexplained injury or medical problems, including oesophageal foreign body impaction.
\end{abstract}

Keywords: Child; Maltreatment; Impacted; Oesophageal Foreign Body; Assault

\section{INTRODUCTION}

Physicians under-report cases of child abuse or child

\footnotetext{
*Competing interest: The authors declare that they have no competing interest.

Author's contribution: AOA was the principal surgeon, perform literature search and prepare the manuscript. AAA assisted in preparing and proof reading the manuscript. ME snapped accompanying images, literature search and assisted in post operative management of the patient. BAN assisted in the surgery, literature search and post operative management of the patient. MGM assisted in the surgery, literature search and post operative management of the patient. KAM assisted in reviewing the manuscript. BA assisted in reviewing the manuscript. $\mathrm{ABM}$ assisted in reviewing the manuscript.
}

maltreatment worldwide. These medical errors may result in continued abuse, leading to potentially severe consequences [1]. These maltreatments include all forms of physical and emotional ill-treatment, sexual abuse, neglect, and exploitation that result in actual or potential harm to the child's health, development or dignity [2].

Ingestion of foreign body is relatively common in the aero-digestive tract among children. However some of them get impacted because of their large size and shapes [3-5], while some frequently swallowed foreign bodies which may pass through the gastrointestinal tract with complication [6]. Oesophageal penetration resulting from foreign body ingestion is uncommon, with the incidence reported to be between $1 \%$ and $4 \%$ [7]. We present a case of oesophageal foreign body impaction in a physically abused child after a written informed consent was obtained from the patient's parents for publication to sensitize the paediatric healthcare giver to include child abuse in the differential of any unexplained injury or medical problem, including impacted oesophageal foreign bodies.

\section{CASE PRESENTATION}

S.H. is a 7-year-old male child of hausa ethinicity who resides with his paternal uncle in the northern part of Nigeria. He was referred from a general hospital (secondary health care provider) to the National Ear Care Centre (NECC) which is a tertiary healthcare provider with 7hrs history of foreign body ingestion and drooling of saliva. He was said to be playing with a metal clip in his mouth when he was being beaten by his uncle which accidentally lead to ingestion of the metal clip.

There had been a past history of uneventful repeated assault from his uncle until the recent one that necessi- 
tated his presentation to the hospital.

He presented with dysphagia and odynophagia but no hematemesis, cough, hemoptysis, respiratory difficulty or hoarseness. There was a positive history of repeated attempted removal at home with stimulation of vomiting and also attempt removal by a general practitioner at the general hospital before referral.

Examination revealed a small for age child weighing $15 \mathrm{~kg}$, height of $0.8 \mathrm{~m}$ apprehensive, not in obvious respiratory distress, not pale, acyanosed, anicteric and afebrile, Oral cavity/Oropharynx examination revealed poor orodental hygiene, pooling and drooling of saliva (Figure 1), tonsils appears normal with granular posterior pharyngeal wall.

Ear, Nose and Neck examination findings were essentially normal.

Assessment of Impacted pharyngo-oesophageal foreign body was made.

Urgent plain radiograph of the soft tissue neck was done which revealed a radio-opaque object of metallic density in the prevertebral soft tissue region extending from lower borders of the $5^{\text {th }}$ to the $7^{\text {th }}$ cervical vertebrae with preservation of the laryngeal air column (Figure 2).

He had an emergency oesophagoscopy with dis-impaction and removal of foreign body under general anaesthesia. The Intraoperative finding were an impacted metal clip with food particles around it with the long limb of the metallic clip buried in the lateral oesophageal mucosal wall about $20 \mathrm{~cm}$ from the upper incisors (Figure 3).

A nasogastric tube was inserted post operatively Intravenous fluid, parenteral antibiotics and steroids were also commenced and supervised graded oral intake started 48 hrs post-operatively. Patient did very well and was discharged home on the $4^{\text {th }}$ post-operative day with no evidence of oesophageal perforation. The parents were counselled on challenges of child abuse and were subsequently referred to a paediatric psychologist.

Follow-up visits in the clinic have been uneventful.

\section{DISCUSSION}

Although so much has been written in the literature about aero-digestive foreign bodies, it is still a problem among the paediatric age group $[3,4]$, as observed in the case presented above. However in adults, true foreign object ingestion occurs in individuals with psychiatric disorders, mental retardation or impairment caused by alcohol, and those seeking some secondary gain with access to a medical facility [8].

The index patient is a 7-year-old which is slightly above the common age group reported [3] but still falls amongst the under 10 years age group reported by Okoye [9]. Our patient is a male which corresponds to previous work done that foreign body ingestion is commoner

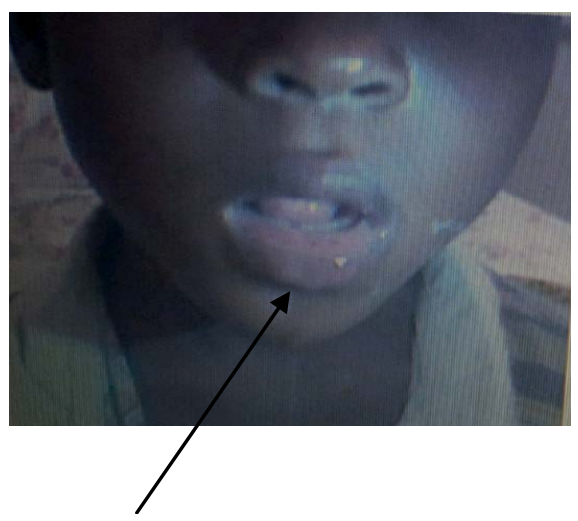

Figure 1. Patient at presentation with drooling of saliva from the mouth.
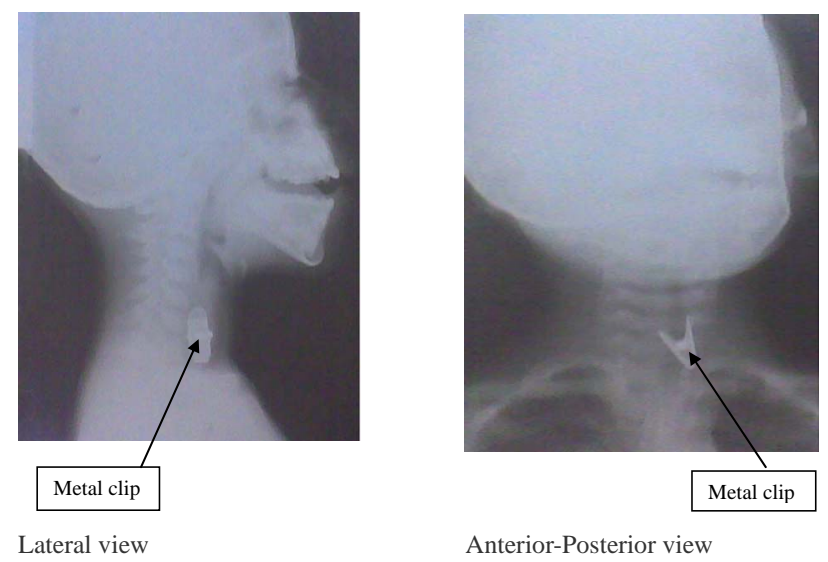

Anterior-Posterior view

Figure 2. X ray soft tissue neck.

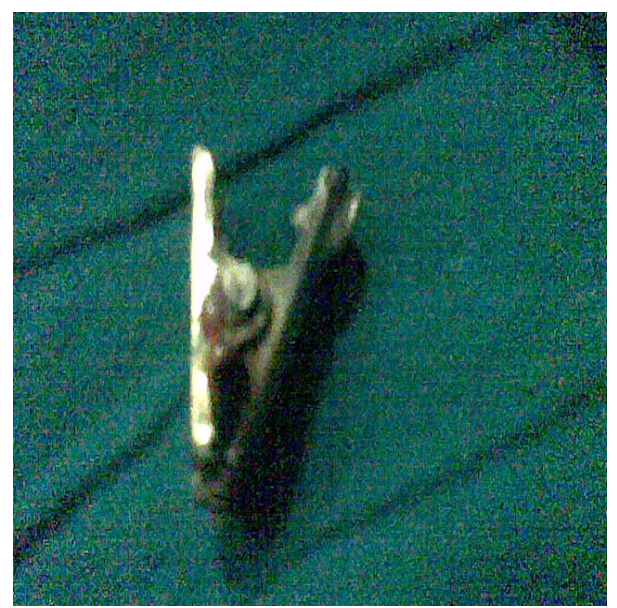

Figure 3. Metallic clip post removal.

among males than females as they are more explorative $[3-5,9]$. Previous reports have found coins $[3,4]$ and fishbone [10]. The child presented with pooling and drooling of saliva, dysphagia, odynophagia which are evidences of foreign body impaction or obstruction of the aero-digestive tracts which generated apprehension among the caregiver and the healthcare provider [3]. The 
index case presented however had good pointing sign which is reliable as against some other report [11]. The circumstances surrounding the foreign body ingestion could have lead to aspiration of the foreign body due to sudden movement which could have led to an emergency laryngoscopy, bronchoscopy or possible death in view of that long duration before presentation to the specialist health care services. Attempts were also made at retrival of the foreign body through stimulation of vomitus, finger insertion into the throat and general practitioner's attempt could as well lead to either aspiration of the foreign body or further impaction of the foreign body with additional risks of other complications such as haematemesis, oesophageal perforation, mediastinitis, pneumothorax, pleural effusion, tracheoesophageal fistula, septicemia, pneumonia, aspiration and sometimes death could result [12].

Child abuse could present in various forms and the primary care clinicians may be the first professionals in a position to begin the evaluation for possible child maltreatment [2] as in the case presented above. The index child was frightened to talk in the presence of the care giver who accompanied him to the emergency department but only volunteered the information after he was left alone with the clinician after he was assured of confidentiality.

The most common site of foreign body impaction in the oesophagus is the cervical oesophagus at the level of the cricopharyngeus which also corresponds to the upper third of the oesophagus, followed by the thoracic oesophagus at the level of the aortic arch, however in the index patient presented the foreign body was retrieved about $20 \mathrm{~cm}$ from the upper incisor which corresponds to the region of the upper third of oesophagus where the foreign body was retrieved. The associated complications with the surgical interventions depends on the skill of the endoscopist [13], if deeply impacted it may require a lateral pharyngotomy [13].

Despite the natural hesitancy to diagnose abuse, clinicians have an ethical and moral obligation to address this issue both in their practice and in their communities. The short-term and long-term costs to individuals who experience family violence have been well demonstrated and included not only emotional repercussions, but also chronic health conditions, which resulted in significant economic costs to society $[1,2]$.

In conclusion, there is a need to increase continuing education on the subject "child maltreatment" and this should focus not only on the identification of maltreatment but also on its management and outcomes. It remains the responsibility of paediatric healthcare providers to consider child maltreatment as a differential diagnosis in any unexplained injury or medical problems, including oesophageal foreign body impaction.

\section{CONSENT}

Written informed consent was obtained from the patient's father for the publication of this case report and any accompanying images. A copy of the written consent is available for review by the editor-in-chief of this journal.

\section{ACKNOWLEDGEMENTS}

The authors are grateful to the anaesthetist who assisted in surgery of this patient. We also thank the patient's father who consented to this report.

\section{REFERENCES}

[1] Flaherty, E.G. and Sege, R. (2005) Barriers to physician identification and reporting of child abuse. Pediatric Annals, 34, 338.

[2] Newton, A.W. and Vandeven, A.M. (2009) Update on child maltreatment. Current Opinion in Pediatrics, 21, 252-261. doi:10.1097/MOP.0b013e328329263d

[3] Afolabi, O.A., Okhakhu, A.L. and Adeosun, A.A. (2009) Re-emergence of coin in Nigerian currency: Implication in medical practice. The Internet Journal of Otorhinolaryngology, 9, 4.

[4] Amadasun, E.O. (1995) Coin as oesophagia foreign body: Effect of change in minting. African Medical Review, 6-8.

[5] Crysdal, W.S., Sendi, K.S. and Yoo, J. (1991) Oesophageal foreign bodies in children: 15 years review of 684 cases. Annals of Otology, Rhinology, and Laryngology, 100, 320-368.

[6] MacManus, J.E. (1941) Perforations of the intestine by ingested foreign bodies: Report of two cases and review of the literature. The American Journal of Surgery, 53, 393-402. doi:10.1016/S0002-9610(41)90652-9

[7] Scher, R.L., Tegtmeyer, C.J. and McLean, W.C. (1990) Vascular injury following foreign body perforation of the esophagus: Review of the literature and report of a case. Annals of Otology, Rhinology, and Laryngology, 99, 698702.

[8] Kamal, I., Thompson, J. and Paquette, D.M. (1999) The hazards of vinyl glove ingestion in the mentally retarded patient with pica: New implications for surgical management. Canadian Journal of Surgery, 42, 201-204.

[9] Okoye, I.J., Imo, A.O. and Okwulehie, V. (2005) Radiologic management of impacted coin in the oesophagusA case report. Nigerian Journal of Clinical Practice, 8 , 56-59.

[10] O’Flynn Simo, R.P. (2007) Fish bones and other foreign bodies. Clinical Otolaryngology, 18, 231-233. doi:10.1111/j.1365-2273.1993.tb00837.x

[11] Connolly, A.A., Birchall, M., Walsh-Waring, G.P. and Moore-Gillon, V. (1992) Ingested foreign bodies: Patient guided localization is a useful clinical tool. Clinical Otolaryngology, 17, 520-524. doi:10.1111/j.1365-2273.1992.tb01710.x 
[12] Hachimi-Idrissi, S., Corne, L. and Vandenplas, Y. (1998) Management of ingested foreign bodies in childhood: Our experience and review of the literature. European Journal of Emergency Medicine, 5, 319-323.

doi:10.1097/00063110-199809000-00007
[13] Waltzman, M.L., et al. (2005) A randomized clinical trial in the management of esophageal coins in children. Pediatrics, 116, 614-619. doi:10.1542/peds.2004-2555 